\title{
Intelligent prediction of optimum separation parameters in the multistage crude oil production facilities
}

\author{
Mohamed Mahmoud ${ }^{1} \cdot$ Zeeshan Tariq $^{1} \cdot$ Muhammad Shahzad Kamal $^{1} \cdot$ Mustafa Al-Naser $^{2}$
}

Received: 7 March 2019 / Accepted: 28 May 2019 / Published online: 3 June 2019

(c) The Author(s) 2019

\begin{abstract}
To obtain the high-quality crude oil from the surface processing plants, oil and gas separation plants parameters need to be optimized, by minimizing the intermediate components, flash from the crude oil during primary and secondary separation processes. The aim of this paper is to present an accurate methodology for predicting optimized separation parameters in the multistage crude oil production unit. The new proposed methodology determines the optimum pressures of separators in different stages of separation and consequently optimizes the operating conditions. A dynamic simulator is used to generate the data set for a designed production facility. Then, an optimization algorithm is used to build an optimum artificial neural network model to predict the optimum operating conditions that will maximize the liquid recovery. The ultimate objective of this work is to have an advisory system for optimizing liquid recovery from the production facilities.
\end{abstract}

Keywords Stage separation · Optimum pressure $\cdot$ Optimum temperature $\cdot$ White box artificial neural network · Advisory system

\begin{tabular}{|c|c|c|c|c|}
\hline \multicolumn{3}{|c|}{ Abbreviations } & AAPE & Average absolute percentage error \\
\hline \multirow{2}{*}{\multicolumn{2}{|c|}{ API }} & American Institute of Petroleum & $\mathrm{PC}$ & Pseudo-component \\
\hline & & Gravity & $b$ & bias \\
\hline \multicolumn{2}{|c|}{ ANN } & Artificial neural network & $w$ & weight \\
\hline \multicolumn{2}{|c|}{ GOR } & Gas oil ratio & $X$ & Input value to neural network \\
\hline \multicolumn{2}{|c|}{ Bob } & Formation volume factor & ${ }^{\circ} \mathrm{R}$ & Rankine temperature degree \\
\hline \multicolumn{2}{|c|}{$N$} & Number of stages & & \\
\hline \multicolumn{2}{|c|}{ ANN } & Artificial neural networks & $\begin{array}{l}\text { LISt of symbols } \\
P\end{array}$ & \\
\hline \multicolumn{2}{|c|}{ FN } & Functional network & $P$ & Pressure \\
\hline \multirow{2}{*}{\multicolumn{2}{|c|}{ SVM }} & Support vector machines & & Temperature \\
\hline & & Decision tree & $\omega$ & Acentric factor \\
\hline \multirow{3}{*}{ FL } & & Fuzzy logic & $K$ & Equilibrium constant \\
\hline & & & $y$ & Gas mole fraction \\
\hline & & & $x$ & Liquid mole fraction \\
\hline \multirow[t]{8}{*}{$凶$} & \multicolumn{2}{|c|}{$\begin{array}{l}\text { Mohamed Mahmoud } \\
\text { mmahmoud@kfupm.edu.sa }\end{array}$} & $n$ & $\begin{array}{l}\text { Total mole fraction in the flow } \\
\text { stream }\end{array}$ \\
\hline & \multirow{2}{*}{\multicolumn{2}{|c|}{$\begin{array}{l}\text { Zeeshan Tariq } \\
\text { g201406240@kfupm.edu.sa }\end{array}$}} & $z$ & Component mole fraction \\
\hline & & & $i-$ & Isomer \\
\hline & \multicolumn{2}{|c|}{ Muhammad Shahzad Kamal } & $n$ - & Normal \\
\hline & \multirow{2}{*}{\multicolumn{2}{|c|}{ 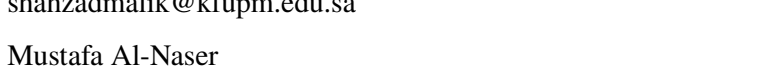 }} & $c_{1}, c_{\text {disp }}$ & Fitting parameters \\
\hline & & & $\sigma$ & Interfacial tension \\
\hline & \multirow{2}{*}{\multicolumn{2}{|c|}{ mustafa.alnasser@sa.yokogawa.com }} & $\mu$ & Viscosity \\
\hline & & & $\rho$ & Density \\
\hline \multirow[t]{2}{*}{1} & \multirow{2}{*}{\multicolumn{2}{|c|}{$\begin{array}{l}\text { College of Petroleum Engineering and Geoscience, King } \\
\text { Fahd University of Petroleum and Minerals, Dhahran 31261, } \\
\text { Saudi Arabia }\end{array}$}} & $D$ & Phase droplet size \\
\hline & & & $k, a, c, F, d$ & Two-phase equilibrium constants \\
\hline
\end{tabular}

2 Yokogawa Saudi Arabia Company, Dhahran Techno-Valley, PO Box 3368, Dhahran, Saudi Arabia 


$$
\begin{array}{ll}
a_{1}, a_{2}, a_{3}, a_{4}, a_{5}, a_{6}, a_{7} & \begin{array}{l}
\text { Fitting parameters from the non- } \\
\text { linear regression } \\
\text { Coefficient of determination }
\end{array} \\
R^{2} &
\end{array}
$$

\section{Subscripts}

ri

ci

$i$

wh

atm

$p$

Disp

$\operatorname{tr}$

opt

norm

$\min$

$\max$

$u$

$v$

\section{Introduction}

The produced oil composition changes along its journey from the reservoir to surface facilities due to the change in pressure and temperature. Crude oil at downhole conditions (high pressure and temperature) may have dissolved gas that maintains the oil light components in equilibrium with the heavier components. When the pressure is reduced, the gas flashes from the oil changing oil composition and properties drastically. Oil and gas separation plants should be optimized to maintain high-quality oil by reducing the intermediate components flashing from the oil during the stage separation period. This can be achieved by optimizing the following parameters: number of stage separations, pressure, and temperature of each stage (Bahadori et al. 2008).

Downhole oil has high gas oil ratio (GOR) compared to the one at the surface (Abdel-Aal et al. 2003). The pressure losses due to potential and friction in the production tubing reduce the pressure of the oil stream that goes to the GOSP (Gas Oil Separation Plant). Separator pressure can be controlled and optimized using the backpressure control valve to maximize the amount of dissolved gas in solution to maximize the liquid recovery. Crude oil consists mainly of light components such as methane, ethane; intermediate components such as propane, butane, pentane, hexane; and heavy components that have $\mathrm{C} 7+$ components. The main objective of surface facilities is to separate the methane and ethane gas from the crude oil and maintain the intermediate components to maximize the liquid recovery. Maintaining the intermediate components in oil enhances the oil quality (higher API) leading to the higher oil price. Several separation methods can be used to separate the gas from oil such as differential and flash separation tests. In differential separation methods, gas is removed from the oil as the pressure is reduced. Previous research showed that differential separation maximized the recovery of the intermediate and heavier components from the oil and higher stock tank oil amount could be obtained (Clark 1969). Ahmed (2001) stated that in the differential separation methods, the separation of gas from oil at high pressures will help maintain to the intermediate and heavy components in the oil. However, the differential separation method is very expensive compared to the flash separation method as the former is difficult to be implemented in the field operations (Abdel-Aal et al. 2003).

Table 1 summarizes the previous work done on GOSP optimization along with the equations or AI models used. Also Table 1 lists the modeling approach that was used and pros and cons of each model.

This paper is organized as follow: first section will explain the current empirical correlations to estimate GOSP parameters, second section will show the proposed artificial intelligence technique, third section will demonstrate and discuss the results.

\section{Empirical correlations}

The optimum number of separation stages is a function of the oil composition, well head pressure; therefore, it may differ from field to another (Gunnerud et al. 2012). During GOSP design, well head pressure declination with time should be considered as it impacts the separator entry pressure (Arnold and Stewart 1999).

Table 2 shows the steps to determine the optimum separation conditions of pressure and temperature using twophase flash calculations. The optimum separator pressure that yields the maximum liquid recovery can be determined from the flash calculations using the vapor/liquid equilibrium method. As listed in the table, the first step is to determine the reduced properties of the gas, reduced pressure and reduced temperature. The two-phase flash calculations depend highly on the equilibrium constants between the liquid and gas phases (k). The two-phase equilibrium constant can be determined as shown in Table 2 (Abhvani and Beaumont 1987) using the gas mole fraction $\left(y_{i}\right)$ and liquid model fraction $\left(x_{i}\right)$. The second step is the material balance calculations in which the optimization will be done on the separator pressure and temperature that maximize the liquid recovery. Table 3 shows the critical properties $P_{c i}$ and $T_{c i}$ and $T_{t r}$ listed in the previous equations that can be used to calculate the $k$-values at a given pressure and temperature to optimize the number of separation stages and the pressure and temperature of each separator. 


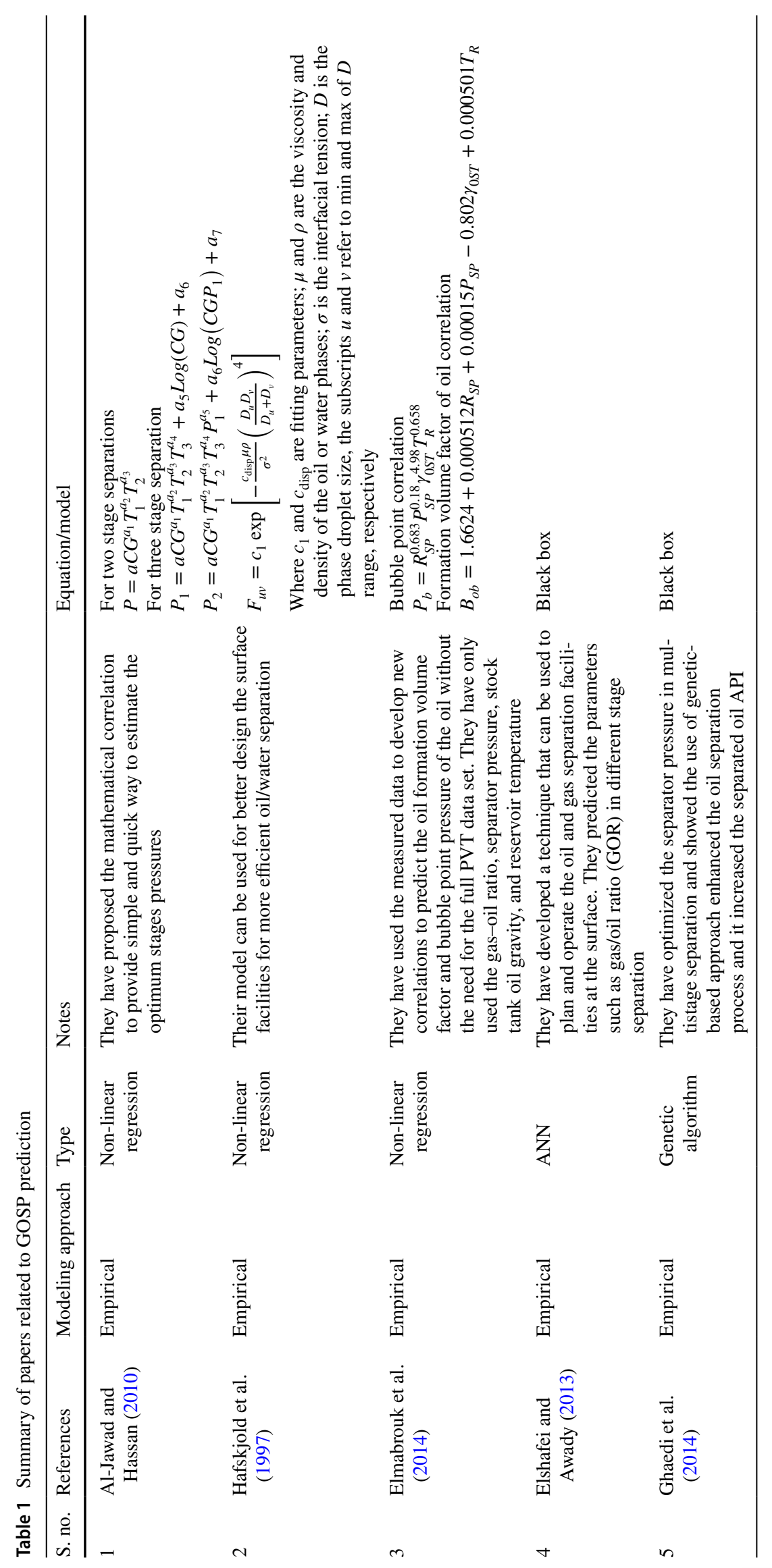


Table 2 Steps of two-phase flash calculations

\begin{tabular}{|c|c|c|}
\hline Step & Description & Equations \\
\hline 1 & $\begin{array}{l}\text { Determine the reduced pressure }\left(P_{r i}\right) \\
\text { and reduced temperature }\left(T_{r i}\right)\end{array}$ & $P_{r i}=\frac{P}{P_{c i}} \quad T_{r i}=\frac{T}{T_{c i}}$ \\
\hline 2 & $\begin{array}{l}\text { Determine equilibrium constant } \\
\text { Two methods can be used }\end{array}$ & $\begin{array}{l}k_{i}=\frac{1}{P_{r i}} e^{5.37\left(1+\omega_{i}\right)\left(1-\frac{1}{T_{r i}}\right)} \\
k_{i}=\left(\frac{1}{p}\right)\left(10^{\left(a+c F_{i}\right)}\right) \\
a=1.2+4.5\left(10^{-4}\right) p-3.5\left(10^{-8}\right) p^{2} \\
c=0.89-1.7\left(10^{-4}\right) p-3.5\left(10^{-8}\right) p^{2} \\
F_{i}=d_{i}\left(\frac{1}{T_{b}}-\frac{1}{T}\right) \quad d_{i}=\frac{\log _{10} \frac{P_{c i}}{14.7}}{\left(\frac{1}{T_{t r}}-\frac{1}{T_{c i}}\right)}\end{array}$ \\
\hline 3 & $\begin{array}{l}\text { Two-phase flash calculations } \\
\text { Material balance }\end{array}$ & $\begin{array}{l}k_{i}=\frac{y_{i}}{x_{i}} \\
n_{l}+n_{g}=1, \sum_{i=1}^{n} x_{i}=\sum_{i=1}^{n} y_{i}=1\end{array}$ \\
\hline & & $\begin{array}{l}x_{i} n_{l}+y_{i} n_{g}=z_{i} \\
x_{i}=\frac{z_{i}}{1+n_{g}\left(k_{i}-1\right)} \\
y_{i}=\frac{k_{i} z_{i}}{1+n_{g}\left(k_{i}-1\right)}\end{array}$ \\
\hline
\end{tabular}

Table 3 Properties of different components

\begin{tabular}{llll}
\hline Component & $P_{c}$, psi & $T_{c},{ }^{\circ} \mathrm{R}$ & $T_{b},{ }^{\circ} \mathrm{R}$ \\
\hline $\mathrm{CO}_{2}$ & 1071 & 547.91 & 350.743 \\
$\mathrm{~N}_{2}$ & 493.1 & 227.49 & 139.549 \\
$\mathrm{H}_{2} \mathrm{~S}$ & 1300 & 672.45 & 383.503 \\
$\mathrm{C} 1$ & 666.4 & 343.33 & 201.27 \\
$\mathrm{C} 2$ & 706.5 & 549.92 & 332.51 \\
$\mathrm{C} 3$ & 616 & 666.06 & 416.25 \\
$\mathrm{i}-\mathrm{C} 4$ & 527.9 & 734.46 & 470.78 \\
$\mathrm{n}-\mathrm{C} 4$ & 550.6 & 765.62 & 491.08 \\
$\mathrm{i}-\mathrm{C} 5$ & 490.4 & 829.1 & 542.12 \\
n-C5 & 488.6 & 845.8 & 556.92 \\
$\mathrm{C} 6$ & 436.9 & 913.6 & 615.72 \\
$\mathrm{C} 7+$ & 396.8 & 972.7 & 669.16 \\
\hline
\end{tabular}

\section{Artificial intelligence}

The modern trend in data analytics and mining is integrating multi-dimensional and multi-modal data for valueadded decision making in petroleum engineering applications. Over the years, various AI techniques have been implemented and attracted attention in various areas of geosciences and petroleum engineering applications (Passos et al. 2014). Many successful implementations of AI techniques in real oil and gas cases have attracted considerable interest in applying these techniques to predict challenging parameters in the petroleum industry. Some of the domains of the petroleum engineering in which AI techniques brought new values includes, porosity-permeability predictions (Abdulraheem et al. 2007; Nooruddin et al.
2013; Helmy et al. 2013; Anifowose et al. 2013), hydraulic flow unit identification (Shujath Ali et al. 2013), geomechanics parameters estimation (Yang and Rosenbaum 2002; Sonmez et al. 2004; Abdulraheem et al. 2009; Cevik et al. 2011; Tariq et al. 2016a, 2017a, b), geophysical well logs estimation (Tariq et al. 2016b; Elkatatny et al. 2018), well test parameters estimation (Artun 2017; Bazargan and Adibifard 2017), asphaltene prediction (Fattahi et al. 2015; Alimohammadi et al. 2017), water saturation prediction (Adebayo et al. 2015; Baziar et al. 2016) and many other oil and gas applications (Ahmadi 2011, 2012, 2015a, b, 2016; Ahmadi and Shadizadeh 2012; Ahmadi et al. 2014a, b, cd, e, f, 2015a, b, c, 2017; Ahmadi and Ebadi 2014; Ahmadi and Bahadori 2015; Ahmadi and Mahmoudi 2016; Ali Ahmadi and Ahmadi 2016). A common traditional AI technique which applied in petroleum engineering applications are: artificial neural networks (ANN), functional network (FN), support vector regressions (SVR's), decision trees (Dt's), and fuzzy logic (FL).

Elmabrouk et al. (2014) used regression analysis to develop a new correlation to predict the oil formation volume factor and bubble point pressure of the oil without the need for the full PVT data set. They only used gas-oil ratio, separator pressure, stock tank oil gravity, and reservoir temperature. They obtained accurate results compared to the actual measured values. Elshafei and Awady (2013) used the neural network technique to predict the performance of the GOSP multistage separation facility. They developed a technique that can be used to plan and operate the oil and gas separation facilities at the surface. They predicted parameters such as gas/oil ratio (GOR) in different stage separation. Ghaedi et al. (2014) used genetic algorithms to optimize the 
Fig. 1 Workflow of the proposed research study to model optimum GOSP parameters

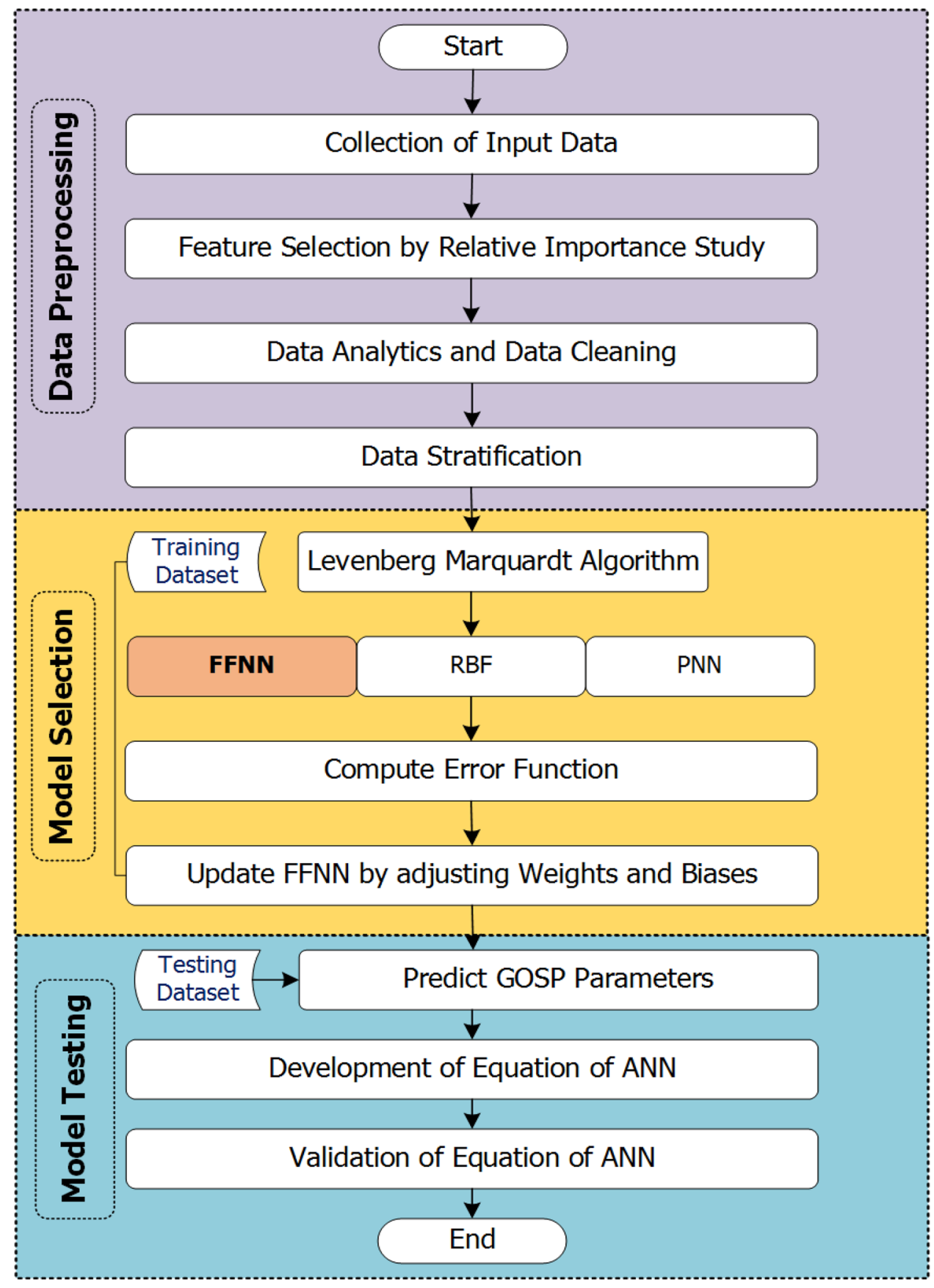

separator pressure in multistage separation. They showed the use of genetic-based approach enhanced the oil separation process and it increased the separated oil API.

This study explores the comparative performance of stateof-the-art and conventional AI techniques in the prediction of optimum separator pressure and the optimum number of stage separation of the GOSP that yields the maximum liquid recovery. The outcome of this study serves to assist users of AI techniques to make informed choices on the appropriate state-of-the-art techniques in petroleum production for improved predictions and better decision making especially when faced with limited and sparse integrated data. White box ANN was used to predict the optimum separation pressure and temperature based on the fluid composition of the flow stream.

Several authors including Elmabrouk et al. (2014) and Elshafei and Awady (2013) proposed a black box type of AI models. In all these papers, authors only mentioned the approach they have used to train their models. Readers of their papers cannot use them to make a prediction on a new dataset. In this study, the ANN model is translated into a simple mathematical model by extracting optimized weights 
Fig. 2 Effect of water cut on oil recovery from the first-stage separation
Fig. 3 Effect of the number of stage separation on the extra oil recovery
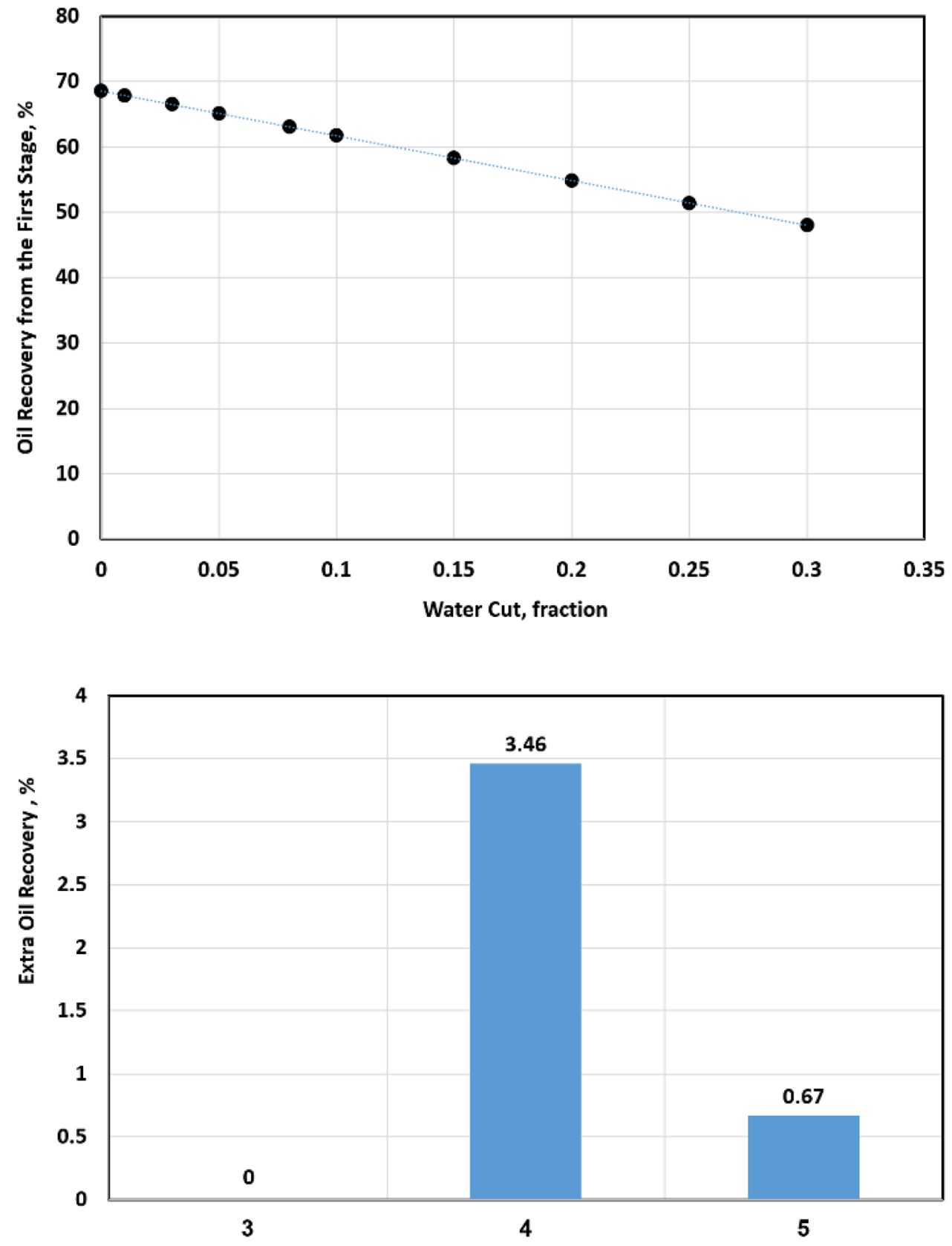

No. of Stage Separation and biases. This will allow readers to use ANN-based mathematical model to predict optimum separator pressure and temperature conditions by simply plug in the required input parameters without the need of using AI software to train ANN first and then make a prediction using trained model.

\section{Optimum separator pressure prediction}

Figure 1 shows the workflow that was followed to optimize the GOSP parameters of pressure and temperature.

To estimate the optimal value of optimum separator pressure, the following procedure is used:
Step 1 Normalize input parameters between -1 and 1 . Input parameters are denoted here by 'Input'. The general equation for normalization is given by Eq. 1 .

$$
X_{\text {norm }}=\frac{\left(\text { Input }_{\max }-\text { Input }_{\text {min }}\right)\left(X-X_{\text {min }}\right)}{X_{\max }-X_{\min }}+\text { Input }_{\min }
$$

$$
\begin{gathered}
\text { Input }_{\text {min }}=-1 \\
\text { Input }_{\max }=1
\end{gathered}
$$


$X$ is the input parameter, $X_{\min }$ is the minimum value of trained input parameter and $X_{\max }$ is the maximum value of the trained input parameter. $X_{\min }$ and $X_{\max }$.

Step 2 Use the Empirical correlation shown in Eq. 8 (Appendix 1) to find the optimal value of the pressure.

Step 3 Equation 8 gives optimum separator pressure in normalized form $\left(P_{\text {norm }}\right)$ which is in the range of [ -1 to 1]. So, optimum separator pressure should be de-normalized and transform into real value form by applying Eqs. 4 and 5.

\section{Optimum separator temperature prediction}

To estimate the optimal value of optimum separator temperature, the following procedure is used:

Step 1 Normalize input temperature between $[-1,1]$ as shown in Eq. 1.

Step 2 Use the Empirical correlation shown in Eq. 9 (Appendix 1) to find the optimal value of the pressure. Step 3 De-normalize optimum separator temperature into real value form by applying Eqs. 6 and 7 .

\section{Results and discussion}

\section{Prediction of the optimum GOSP parameters using analytical techniques}

In this part, the number of stage separation that yields the maximum liquid recovery will be predicted as well as the effect of water cut. The optimum pressure and temperature of each stage separation will be determined also based on the maximum liquid recovery. Table 2 equation list was used in this prediction for the oil stream composition listed in Table 3 . The following stream properties and conditions are used: oil flow rate $=66,000 \mathrm{BPD}$, oil viscosity $=0.55 \mathrm{cP}$, $\mathrm{GOR}=910 \mathrm{MSCF} / \mathrm{bbl}$, first-stage separation pressure $=640$ psi.

\section{Effect of water cut on the liquid recovery (oil)}

The effect of water cut on the liquid recovery from the firststage separation is shown in Fig. 2. The water cut highly affected the liquid recovery from the first-stage separation as shown in the figure. The liquid recovery dropped from $68.6 \%$ at zero water cut to $48 \%$ at $30 \%$ water cut of the flow stream. Assuming that the majority of the water will be separated from the first-stage separation and the oil entering the other stages is water free, the liquid recovery is no longer function of the well stream water cut. Water cut does not affect the number of stage separations, but it only affects the first-stage efficiency because it affects the amount of liquid to the gas molar ratio in the first-stage separation which, in turn, affects the equilibrium constant calculations. This example shows that precaution should be taken when higher water cuts are encountered during the separation process because the water will highly impact the process of oil separation. The majority of oil fields starts producing with very low water cuts (some of them start with zero water cut). Due to water influx at later stages, the water production will increase dramatically, and water cut may reach $95 \%$ or more in some fields. During the GOSP design phase, water cut change along the field life should be considered.
Fig. 4 Optimum pressure for the first-stage separation

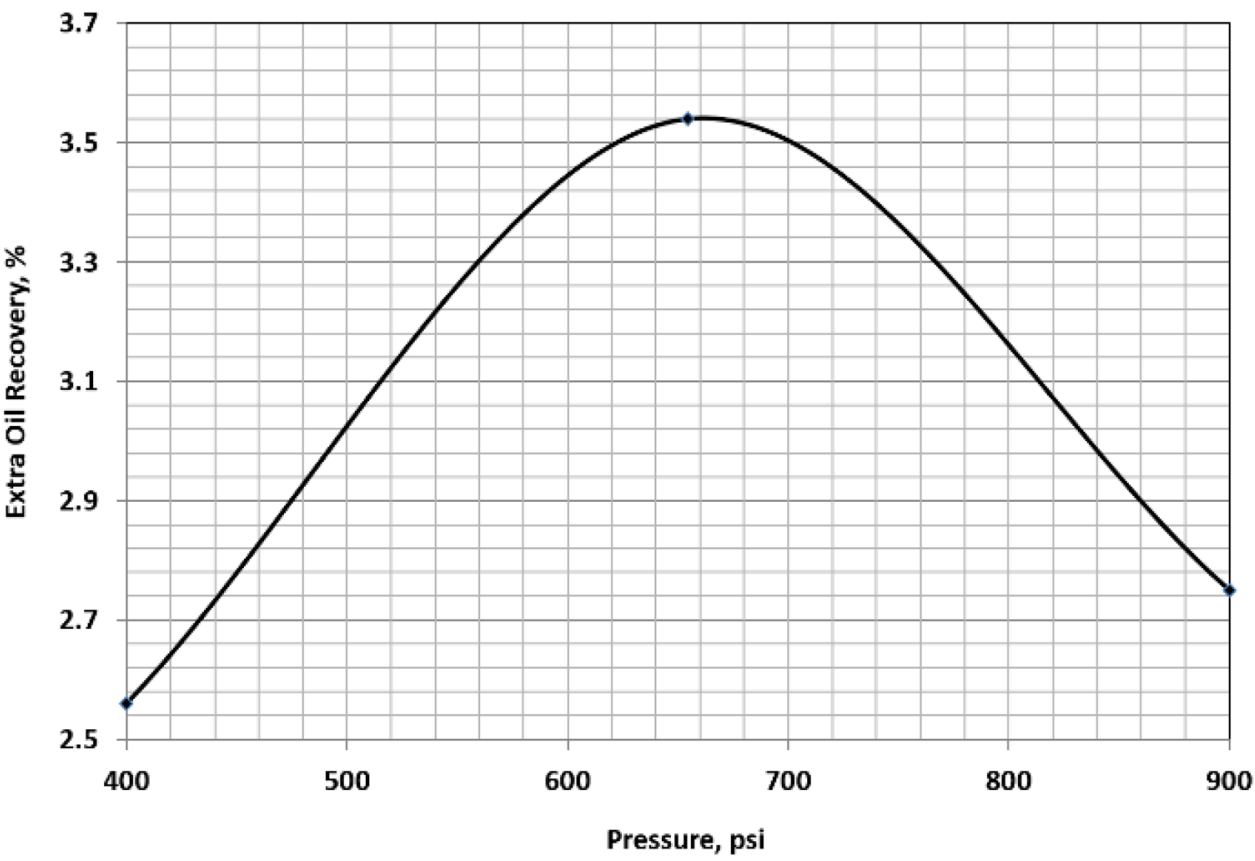

Pressure, psi

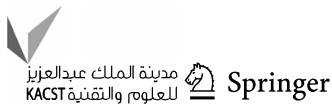


Fig. 5 Optimum temperature for the first-stage separation
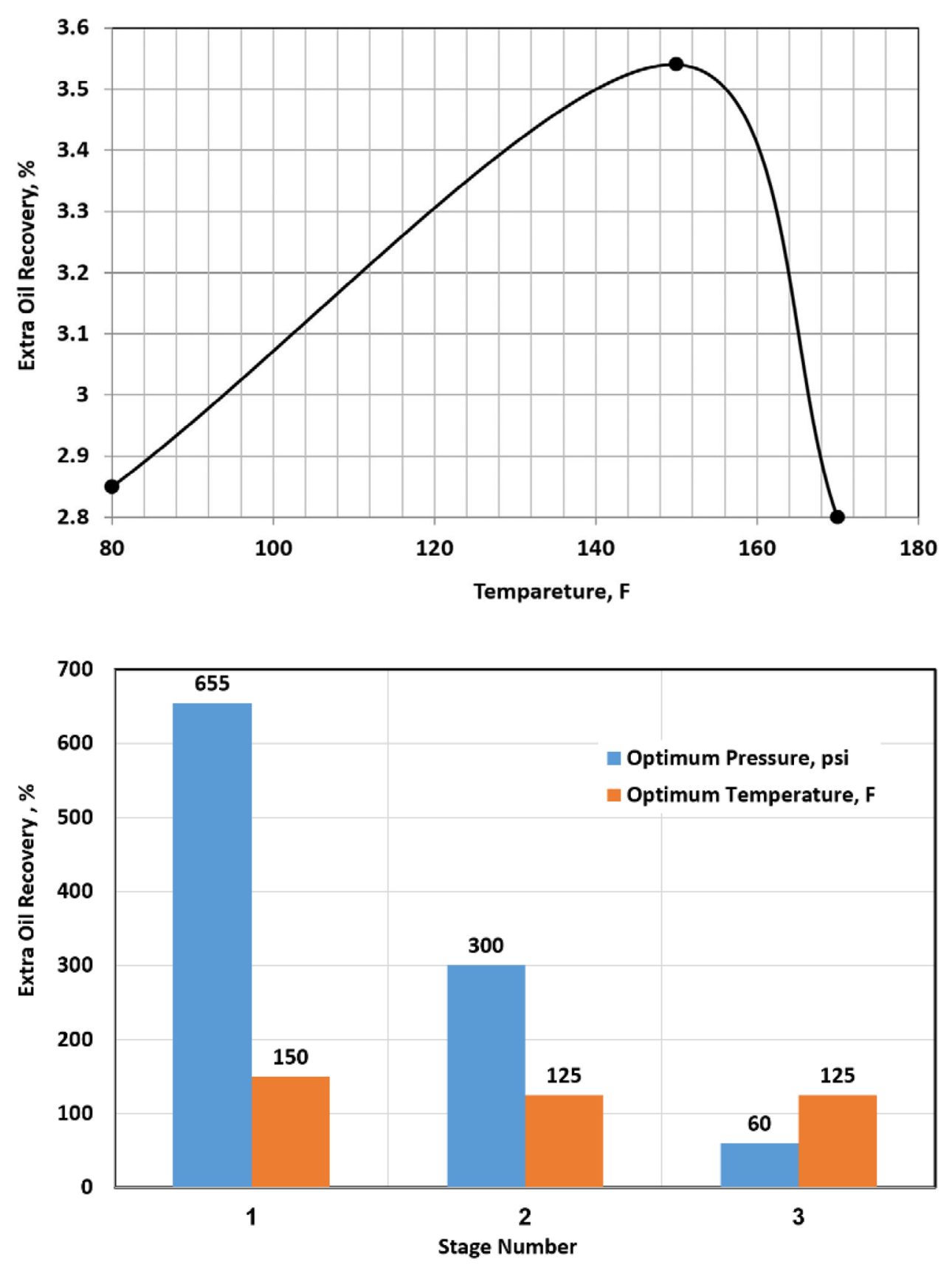

Fig. 6 Optimum pressure and temperature for the three stages

\section{Effect of number of stage separation on the extra oil recovery}

Figure 3 shows the effect of the number of stage separation on the liquid recovery from the GOSP. The extra recovery tested in this example is defined as the difference between the recovery between the two successive stages. Three stage separations did not yield in incremental oil recovery for the flow stream given in the tested example. The four-stage separation was the optimum number that yields the maximum incremental oil recovery of about $3.5 \%$ excess recovery compared to $0.67 \%$ of the five-stage separation. Based on the field practice, if the incremental liquid recovery between the stage separations is less than $1 \%$, the extra stage should not be considered because it will not be feasible from the economic point of view. Increasing the number of separation stages from three to four minimized the gas flash from the oil by keeping the gas in contact with the oil which maximized the oil recovery. Increasing the number of GOSP separations will allow for the small decrement in the separator pressures for the successive stages. As the liquid recovery is a strong function of the separator pressure, the flow stream coming from the wellhead or from the manifold should be adjusted based on the optimum separator pressure to yield 

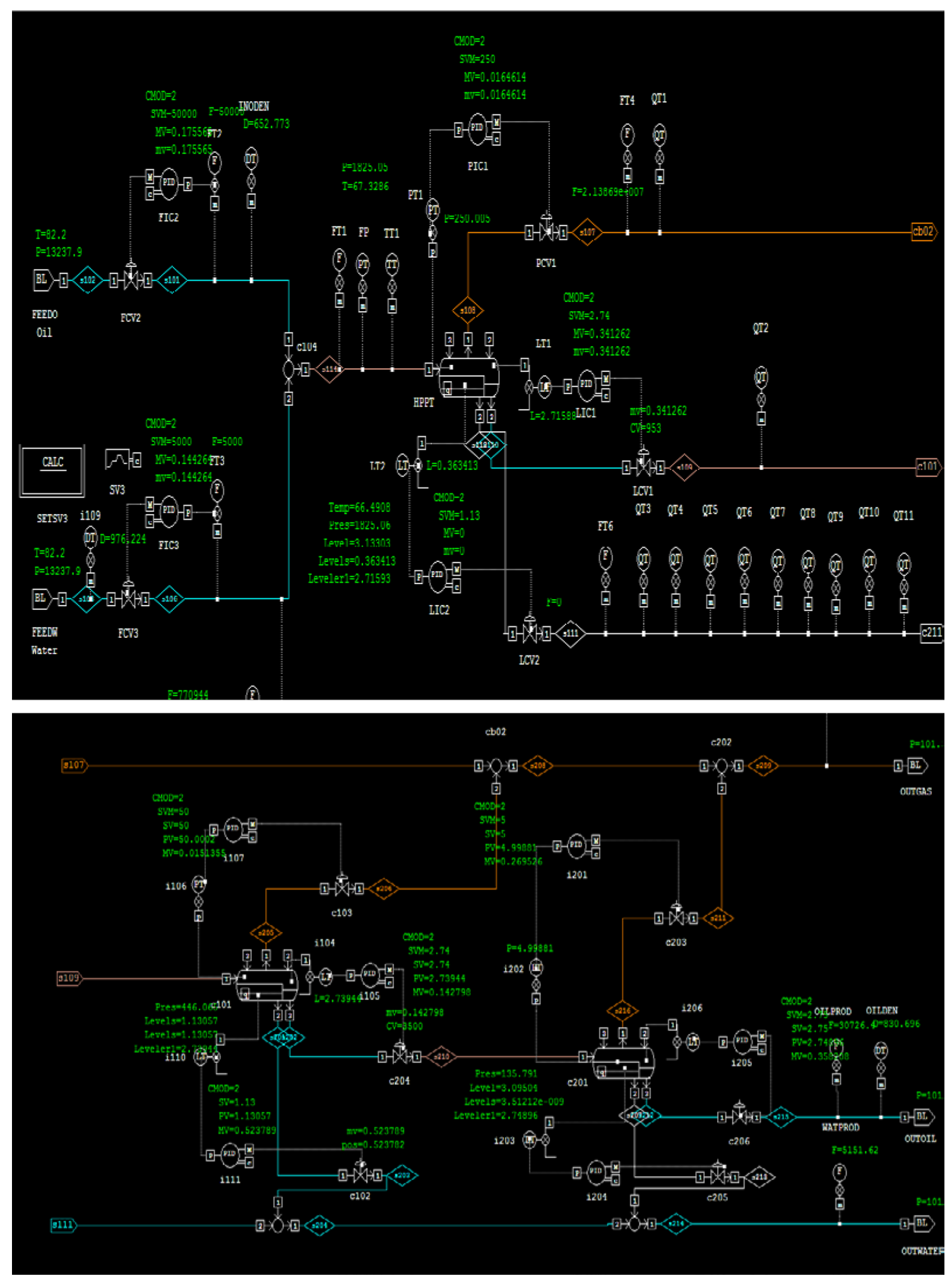

Fig. 7 GOSP model 
Table 4 Data statistics

\begin{tabular}{|c|c|c|c|c|c|}
\hline \multirow[t]{2}{*}{ Parameters } & \multicolumn{5}{|l|}{ Statistics } \\
\hline & Min & $\operatorname{Max}$ & Range & Mean & SD \\
\hline $\mathrm{H}_{2} \mathrm{~S}$ & 0.005 & 0.009 & 0.004 & 0.007 & 0.001 \\
\hline $\mathrm{N}_{2}$ & 0.000 & 0.000 & 0.000 & 0.000 & 0.000 \\
\hline $\mathrm{CO}_{2}$ & 0.001 & 0.002 & 0.001 & 0.001 & 0.000 \\
\hline $\mathrm{C}_{1}$ & 0.000 & 0.001 & 0.001 & 0.001 & 0.000 \\
\hline $\mathrm{C}_{2}$ & 0.003 & 0.006 & 0.003 & 0.005 & 0.001 \\
\hline $\mathrm{C}_{3}$ & 0.010 & 0.018 & 0.007 & 0.015 & 0.002 \\
\hline$i-\mathrm{C}_{4}$ & 0.003 & 0.004 & 0.001 & 0.004 & 0.000 \\
\hline$n-\mathrm{C}_{4}$ & 0.015 & 0.019 & 0.004 & 0.017 & 0.001 \\
\hline$i-\mathrm{C}_{5}$ & 0.008 & 0.009 & 0.001 & 0.008 & 0.000 \\
\hline$n-\mathrm{C}_{5}$ & 0.015 & 0.016 & 0.001 & 0.016 & 0.000 \\
\hline$n-\mathrm{C}_{6}$ & 0.019 & 0.019 & 0.000 & 0.019 & 0.000 \\
\hline $\mathrm{C}_{30+}$ & 0.050 & 0.052 & 0.002 & 0.051 & 0.000 \\
\hline $\mathrm{H}_{2} \mathrm{O}$ & 0.627 & 0.649 & 0.022 & 0.636 & 0.005 \\
\hline $\mathrm{PC}_{1}$ & 0.004 & 0.004 & 0.000 & 0.004 & 0.000 \\
\hline $\mathrm{PC}_{2}$ & 0.002 & 0.002 & 0.000 & 0.002 & 0.000 \\
\hline $\mathrm{PC}_{3}$ & 0.058 & 0.062 & 0.004 & 0.061 & 0.001 \\
\hline $\mathrm{PC}_{4}$ & 0.017 & 0.017 & 0.000 & 0.017 & 0.000 \\
\hline $\mathrm{PC}_{5}$ & 0.051 & 0.053 & 0.002 & 0.052 & 0.000 \\
\hline $\mathrm{PC}_{6}$ & 0.083 & 0.086 & 0.003 & 0.084 & 0.001 \\
\hline Optimum pressure & 208.88 & 257.35 & 48.46 & 232.23 & 11.26 \\
\hline Optimum temperature & 63.200 & 65.982 & 2.782 & 64.871 & 0.900 \\
\hline
\end{tabular}

Table 5 Error analysis

\begin{tabular}{llllll}
\hline $\begin{array}{lllll}\text { Performance } \\
\text { measure }\end{array}$ & \multicolumn{2}{l}{$\begin{array}{l}\text { Optimum separator pres- } \\
\text { sure }\end{array}$} & & \multicolumn{2}{l}{$\begin{array}{l}\text { Optimum separator } \\
\text { temperature }\end{array}$} \\
\cline { 2 - 3 } & Training & Testing & & Training & Testing \\
\hline$R^{2}$ & 0.98 & 0.99 & & 0.99 & 0.995 \\
AAPE & 1.6 & 1.4 & & 1.1 & 0.65 \\
\hline
\end{tabular}

the maximum liquid recovery. The flow stream pressure is a strong function of the wellhead pressure and the distance from the wellhead to the GOSP location. Pressure losses in the pipelines will reduce the pressure at the GOSP. Wellhead pressure depends on the flow mode. In the case of natural flowing well, it ranges from 100 to 500 psi. In artificially lifted wells, the wellhead pressure could be higher than 500 psi.

\section{Optimum pressure and temperature of the separation stage}

The optimum separator pressure and temperature were calculated based on the flash calculations considering the well stream of constant composition. Composition variation during field life can be adjusted by providing the new stream composition.
Table 6 Neural network architecture

\begin{tabular}{ll}
\hline Neural network parameters & Ranges \\
\hline Number of inputs & 9 \\
Number of outputs & 1 \\
Number of neurons & 10 \\
Number of hidden layer(s) & 1 \\
Training algorithm & Levenberg-Marquardt \\
Learning rate, $\alpha$ & 0.12 \\
Hidden layer transfer function & Tan-sigmoidal \\
Outer layer transfer function & Pure linear \\
Training ratio & 0.7 \\
Testing ratio & 0.15 \\
Validation ratio & 0.15 \\
\hline
\end{tabular}

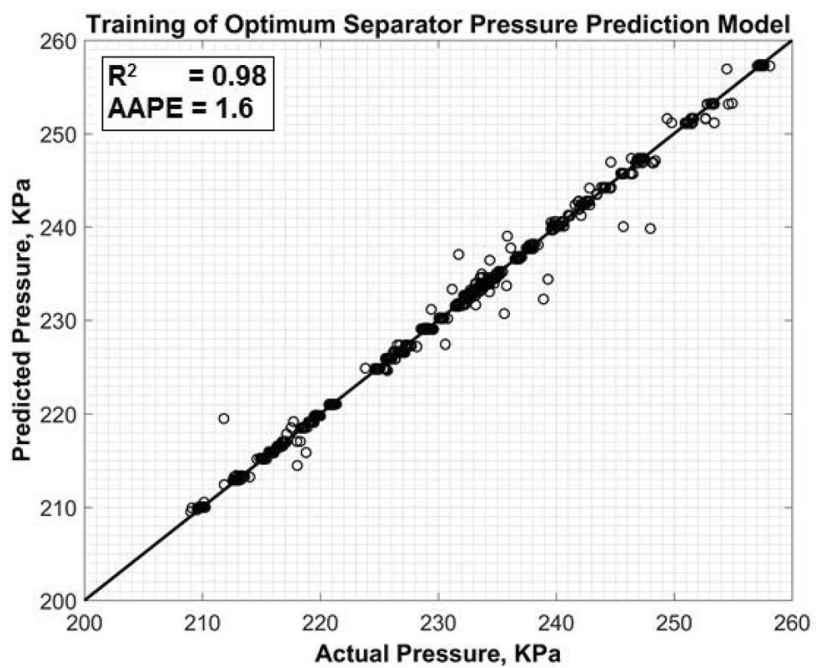

Fig. 8 Training of ANN model to predict the optimum separator pressure

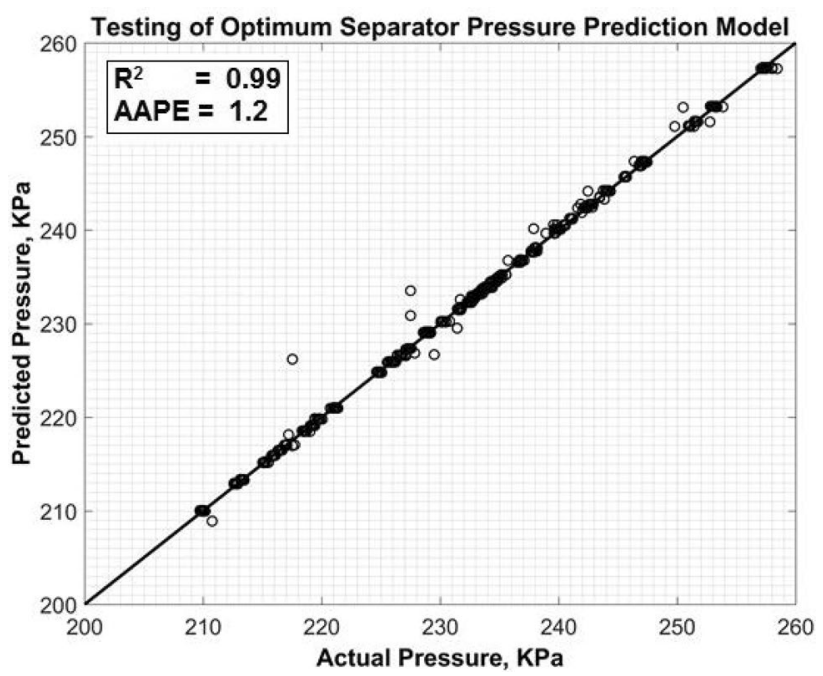

Fig. 9 Testing of ANN model to predict the optimum separator pressure 


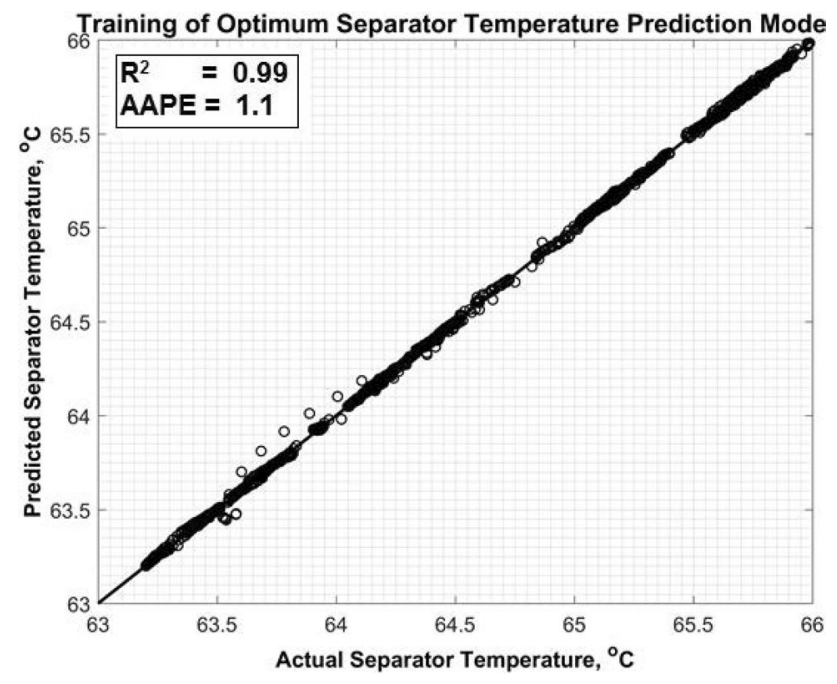

Fig. 10 Training of ANN model to predict the optimum separator temperature

The maximum liquid recovery was calculated based on the list of equations and steps in Table 2 at different separator pressures and temperatures and the equilibrium constant was calculated at these conditions. This method is very simple and accurate compared to the optimization of separation conditions based on wellhead pressure and stock tank atmospheric pressure.

Ling et al. (2013) provided an approximation to determine the optimum separator pressure based on the wellhead pressure. Applying their method for the tested example, where we have four-stage separation:

Ratio $_{p}=\left[\frac{p_{\text {wh }}}{p_{\text {atm }}}\right]^{\frac{1}{N}}=\left[\frac{300}{14.7}\right]^{\frac{1}{3}}=2.73$

The wellhead pressure, in this case, was 300 psi, and the stock tank pressure is atmospheric pressure; $N$ is the number of stage separation -1 . Then, the primary separator pressure can be determined as follows:

$p_{\text {primary }}=\frac{p_{\text {wh }}}{\text { Ratio }_{p}}=\frac{300}{2.73}=110 \mathrm{psi}$

Comparing this pressure to the one obtained based on the flash calculations which is $655 \mathrm{psi}$, there is a big difference between the two methods. The method suggested by Ling et al. (2013) does not consider the changes in wellhead pressure. In addition, Ling et al. (2013) method is not applicable for wells with very low wellhead pressures. On the other hand, our method does not depend on the wellhead pressure, the flow stream composition is needed, and the optimization process will be done independently.

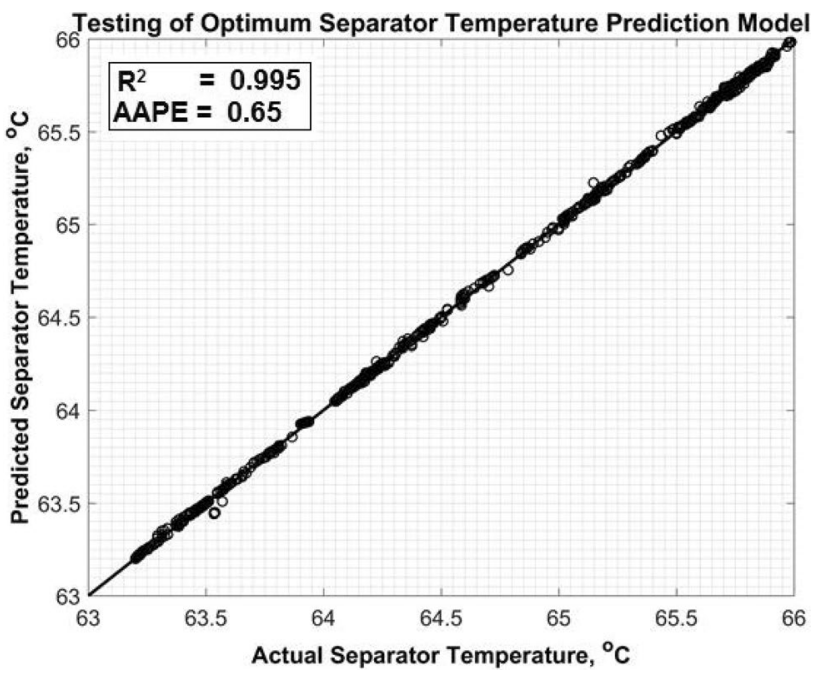

Fig. 11 Testing of ANN model to predict the optimum separator temperature

Figures 4, 5 and 6 show the optimum separator pressure and temperature for the different stage separations. The optimum pressure in the first-stage separation is $655 \mathrm{psi}$, which is usually higher compared to the wellhead pressure. Also, we should consider the pressure losses due to potential energy loss and friction in the pipelines as well as restrictions, orifices, and valves. This means the well stream should be pumped to increase the inlet pressure of the separator to achieve the required optimum value. The GOSP design should consider these optimum pressures to maximize the liquid recovery from the separation process. Based on the flow rate of the well stream, the temperature at the surface could be very close to the one required at the separator to maximize the liquid recovery. The effect of temperature in other stages is negligible compared to the pressure effect. The optimum separator conditions should be performed based on the maximum liquid recovery, and then other properties such as API and GOR can be calculated. However, if optimization was done based on the maximum API and the lowest GOR, the results should be close to one based on maximum liquid recovery. Bahadori et al. (2008) determined the optimum separator conditions based on flash equilibrium during the summer and winter for a specific oil type. They have done their optimization based on the maximum oil API and the minimum GOR, and they obtained an optimum separator pressure of $600 \mathrm{psi}$ during the summer and 100 psi during the winter time due to the change in temperature.

\section{Prediction of the optimum GOSP parameters using artificial intelligence techniques}

Artificial neural network technique was used to train and test the input data to extract the empirical correlation that can 
be used to predict both pressure and temperature that yield the maximum liquid recovery from the GOSP. We created a GOSP model using industrial dynamic process simulator called "OmegaLand" to generate the data as shown in Fig. 7. The optimization was done for the first-stage separation in this study. Table 4 shows the statistics of the input data in which $70 \%$ was used for training and 30\% used for testing. Figures 8 and 9 show the training and testing of the ANN model to predict the separator pressure. Figures 10 and 11 show the training and testing of the ANN model to predict the separator temperature.

\section{Optimum separator pressure estimation}

An empirical expression based on weights and biases of the trained ANN model is developed to model and predict the optimum separator pressure. These weights $\left(w_{1}\right.$ and $\left.w_{2}\right)$ and biases $\left(b_{1}\right.$ and $\left.b_{2}\right)$ for optimum separator pressure prediction model are given in Table 7. The proposed optimum separator pressure ANN equation is given by Eq. 8 (Appendix 1). As mentioned before, the estimated optimum pressure value using Eq. 8 is normalized and it should be de-normalized and transformed into real form as shown below:

$$
\begin{aligned}
& P_{\mathrm{opt}}=\frac{(257.345-208.887)\left(P_{\mathrm{norm}}+1\right)}{2}+208.887 \\
& P_{\mathrm{opt}}=24.229 * P_{\text {norm }}+233.116
\end{aligned}
$$

\section{Mathematical model for optimum separator temperature}

An empirical expression based on weights and biases of the trained ANN model is developed to model predict optimum separator temperature. These weights $\left(w_{1}\right.$ and $\left.w_{2}\right)$ and biases $\left(b_{1}\right.$ and $\left.b_{2}\right)$ for optimum separator temperature prediction model are given in Table 8 . The proposed optimum separator temperature ANN equation is given by Eq. 9 (Appendix 1). As mentioned before, the estimated optimum pressure value using Eq. 9 is normalized and it should be de-normalized and transformed into real form as shown below:

$$
\begin{aligned}
& T_{\mathrm{opt}}=\frac{(65.982-63.2)\left(T_{n}+1\right)}{2}+63.2 \\
& T_{\mathrm{opt}}=1.391 * T_{n}+64.591
\end{aligned}
$$

Table 5 shows the error analysis for both separator pressure and temperature predictions. The coefficient of determination $\left(R^{2}\right)$ and the average absolute percentage error (AAPE) indicate that the empirical correlation extracted from the ANN model is accurate enough to predict the separator pressure and temperature in both testing and training phases. The architecture of the trained ANN model is given in Table 6.

\section{Conclusions}

In this study, the optimum GOSP pressure and temperature based on the fluid composition was determined based on analytical and AI techniques. The separator pressure was found to have a significant effect on the oil recovery from the individual separation stage. Artificial neural network (ANN) was used to predict the optimum pressure and temperature with high accuracy. This means with the fluid composition as inputs, the separator pressure and temperature can be predicted using the developed AI model.

Acknowledgements The authors would like to thank Yokogawa Saudi Arabia for funding and supporting this research under Project SE2384.

Open Access This article is distributed under the terms of the Creative Commons Attribution 4.0 International License (http://creativeco mmons.org/licenses/by/4.0/), which permits unrestricted use, distribution, and reproduction in any medium, provided you give appropriate credit to the original author(s) and the source, provide a link to the Creative Commons license, and indicate if changes were made.

\section{Appendix 1: Empirical correlations}

See Tables 7 and 8. 
Table 7 Weights and biases of trained ANN model to predict optimum separator pressure

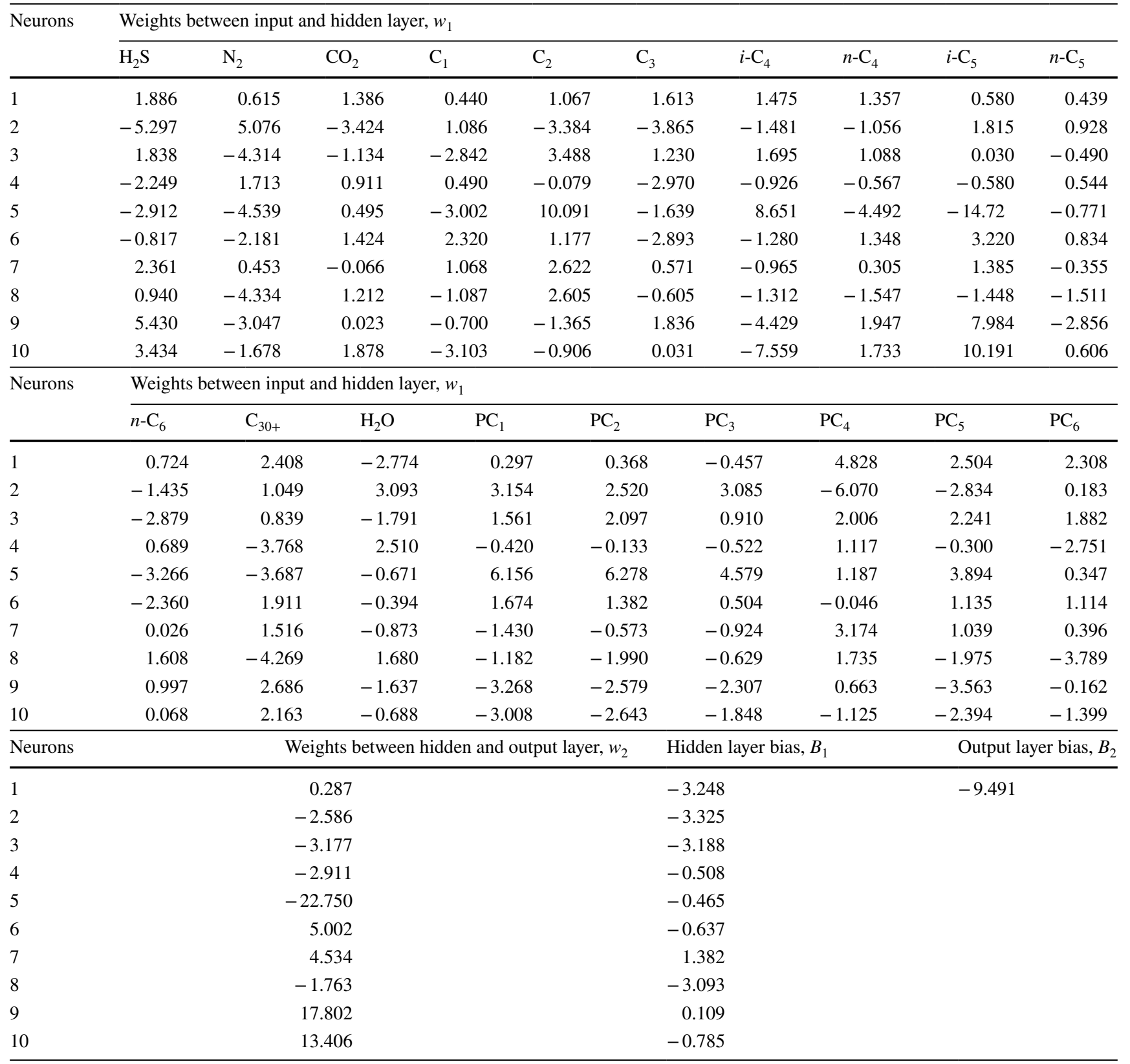


Table 8 Weights and biases of ANN model to predict optimum separator temperature

\begin{tabular}{|c|c|c|c|c|c|c|c|c|c|c|}
\hline \multirow[t]{2}{*}{ Neurons } & \multicolumn{10}{|c|}{ Weights between input and hidden layer, $w_{1}$} \\
\hline & $\mathrm{H}_{2} \mathrm{~S}$ & $\mathrm{~N}_{2}$ & $\mathrm{CO}_{2}$ & $\mathrm{C}_{1}$ & $\mathrm{C}_{2}$ & $y_{3}$ & $i-\mathrm{C}_{4}$ & $n-\mathrm{C}_{4}$ & $i-\mathrm{C}_{5}$ & $n-\mathrm{C}_{5}$ \\
\hline 1 & -0.080 & -2.924 & 3.067 & 0.530 & 0.683 & 0.512 & -0.159 & -0.372 & 0.546 & -0.139 \\
\hline 2 & 0.578 & 1.805 & 0.610 & 1.196 & 0.644 & 0.331 & -0.531 & -0.753 & -0.242 & -0.807 \\
\hline 3 & 1.317 & 0.770 & -1.708 & 0.633 & 2.799 & -1.993 & -2.113 & -1.746 & -0.982 & -0.230 \\
\hline 4 & -0.951 & 0.089 & 1.342 & -0.677 & -0.723 & -0.706 & -1.022 & -0.921 & -0.564 & 0.205 \\
\hline 5 & -1.702 & 1.429 & 4.134 & 0.114 & -5.266 & 1.362 & 0.058 & 0.176 & -0.904 & 1.943 \\
\hline 6 & -0.653 & -0.729 & 0.442 & -0.019 & -0.596 & 0.035 & 0.302 & 0.193 & -0.302 & 0.547 \\
\hline 7 & 3.079 & 0.356 & -6.760 & 2.126 & 3.752 & -3.030 & 0.307 & 0.495 & 1.525 & 1.062 \\
\hline 8 & -0.395 & -4.289 & 7.586 & -1.825 & -3.082 & 1.262 & 0.550 & 1.867 & -0.611 & 2.364 \\
\hline 9 & 2.535 & -1.475 & -1.906 & -0.037 & 2.899 & -3.103 & 0.598 & 0.722 & -0.118 & 1.430 \\
\hline 10 & 0.486 & -0.414 & 0.314 & 0.491 & 1.098 & -1.032 & -1.205 & -0.555 & -1.423 & -0.732 \\
\hline \multirow[t]{2}{*}{ Neurons } & \multicolumn{10}{|c|}{ Weights between input and hidden layer, $w_{1}$} \\
\hline & $n-\mathrm{C}_{6}$ & $\mathrm{C}_{30+}$ & $\mathrm{H}_{2} \mathrm{O}$ & $\mathrm{PC}_{1}$ & $\mathrm{PC}_{2}$ & & $\mathrm{PC}_{3}$ & $\mathrm{PC}_{4}$ & $\mathrm{PC}_{5}$ & $\mathrm{PC}_{6}$ \\
\hline 1 & -0.729 & 2.264 & -1.323 & 0.943 & 0.935 & & 0.348 & -0.188 & 0.413 & 1.188 \\
\hline 2 & -1.880 & 1.221 & 0.208 & -0.434 & -1.028 & & -0.780 & -0.818 & -0.209 & 1.054 \\
\hline 3 & 0.227 & -3.914 & 1.566 & -0.023 & 0.292 & & -0.251 & 0.848 & -0.470 & -1.913 \\
\hline 4 & 3.100 & -1.948 & 1.426 & -0.718 & -0.595 & & -0.258 & 0.446 & -0.788 & -1.815 \\
\hline 5 & -0.109 & 3.257 & -0.717 & 0.048 & -0.224 & & 0.742 & -0.129 & -0.347 & 1.207 \\
\hline 6 & -0.164 & -0.135 & 0.077 & 0.433 & -0.084 & & -0.105 & -1.427 & -0.494 & -0.815 \\
\hline 7 & -2.984 & -1.094 & -0.124 & 1.395 & 2.546 & & -0.148 & 0.967 & 3.602 & 0.944 \\
\hline 8 & -0.201 & -0.331 & 0.019 & -1.495 & -2.447 & & -0.196 & 0.454 & -1.170 & -1.179 \\
\hline 9 & -0.764 & -1.245 & -0.488 & 0.073 & 0.853 & & -0.648 & 1.293 & 1.309 & 0.481 \\
\hline 10 & 1.406 & -3.616 & 0.907 & -1.572 & -1.232 & & -0.415 & 1.368 & -1.474 & -2.587 \\
\hline \multicolumn{2}{|l|}{ Neurons } & \multicolumn{4}{|c|}{ Weights between hidden and output layer, $w_{2}$} & \multicolumn{3}{|c|}{ Hidden layer bias, $B_{1}$} & \multicolumn{2}{|c|}{ Output layer bias, $B_{2}$} \\
\hline 1 & \multicolumn{5}{|c|}{-3.542} & \multicolumn{3}{|c|}{-0.893} & \multicolumn{2}{|l|}{-5.723} \\
\hline 2 & \multicolumn{4}{|c|}{-0.114} & \multicolumn{4}{|c|}{-0.396} & & \\
\hline 3 & \multicolumn{4}{|c|}{2.605} & \multicolumn{4}{|c|}{0.054} & & \\
\hline 4 & \multicolumn{4}{|c|}{-1.166} & \multicolumn{4}{|c|}{0.118} & & \\
\hline 5 & \multicolumn{4}{|c|}{-10.259} & \multicolumn{4}{|c|}{-0.738} & & \\
\hline 6 & \multicolumn{4}{|c|}{-1.872} & \multicolumn{4}{|c|}{0.310} & & \\
\hline 7 & \multicolumn{4}{|c|}{11.173} & \multicolumn{4}{|c|}{0.681} & & \\
\hline 8 & \multicolumn{4}{|c|}{-6.947} & \multicolumn{4}{|c|}{0.585} & & \\
\hline 9 & \multicolumn{4}{|c|}{9.923} & & 0.0 & & & & \\
\hline 10 & & & 139 & & & -0.8 & & & & \\
\hline
\end{tabular}

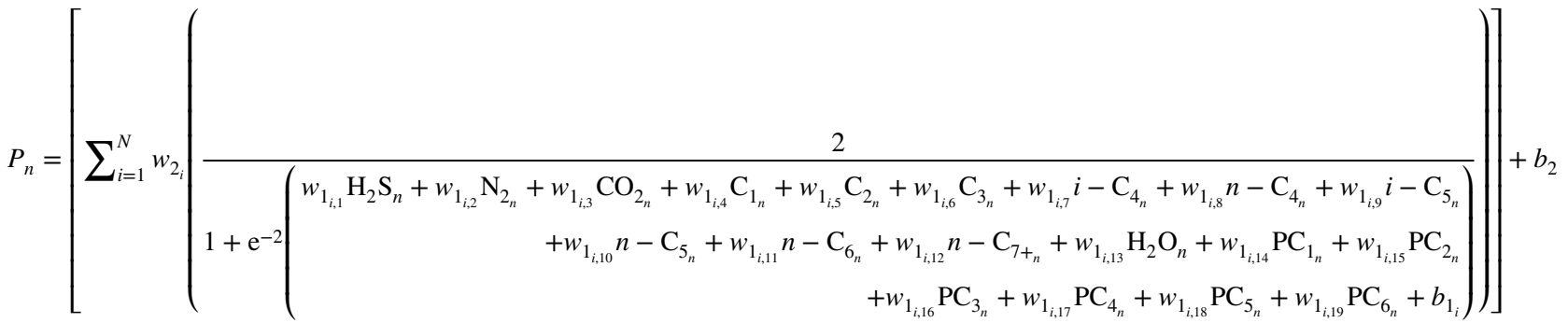




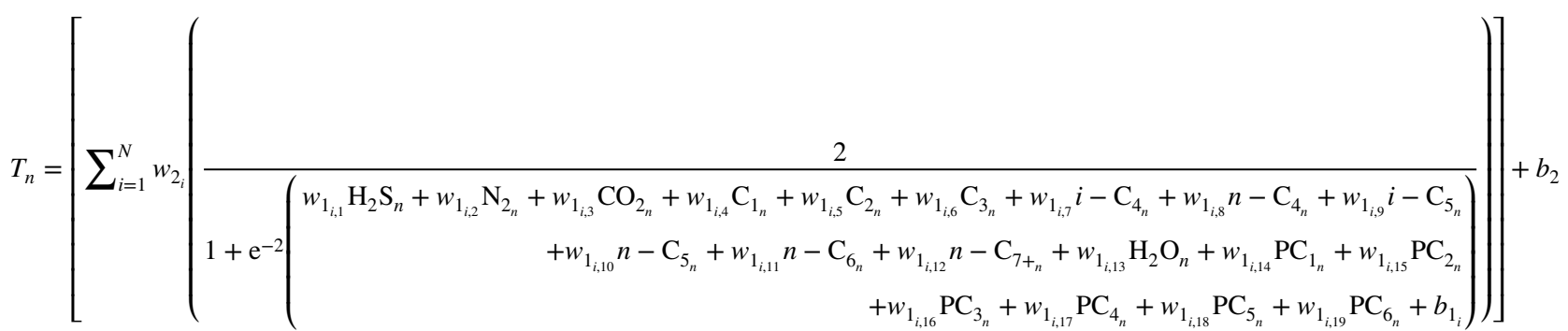

\section{Appendix 2: Error metrics}

Average absolute percentage error (AAPE) is defined as follows

AAPE $=\frac{\sum\left|\left(X_{\text {measured }}-X_{\text {predicted }}\right)\right| * \frac{100}{X_{\text {measured }}}}{k}$

Root-mean-square error (RMSE) is defined as follows

$\mathrm{RMSE}=\sqrt{\frac{\sum\left(X_{\text {measured }}-X_{\text {predicted }}\right)^{2}}{k}}$

where $X_{\text {measured }}$ is the measured value and $X_{\text {predicted }}$ is the estimated value from the models. $k$ is the total number of data points.

Pearson correlation coefficient $\mathrm{CC}$ is defined as follows

$\mathrm{CC}=\frac{k \sum x y-\left(\sum x\right)\left(\sum y\right)}{\sqrt{k\left(\sum x^{2}\right)-\left(\sum y\right)^{2}} \sqrt{k\left(\sum b^{2}\right)-\left(\sum b\right)^{2}}}$

where $x$ and $y$ are two variables.

Coefficient of determination $R^{2}$ is defined as follows

$R^{2}=\left(\frac{k \sum x y-\left(\sum x\right)\left(\sum y\right)}{\sqrt{k\left(\sum x^{2}\right)-\left(\sum y\right)^{2}} \sqrt{k\left(\sum b^{2}\right)-\left(\sum b\right)^{2}}}\right)^{2}$

\section{References}

Abdel-Aal H, Fahim M, Aggour M (2003) Petroleum and gas field processing. CRC Press, Boca Raton

Abdulraheem A, Sabakhy E, Ahmed M et al (2007) Estimation of permeability from wireline logs in a middle eastern carbonate reservoir using fuzzy logic. In: SPE Middle East Oil and Gas Show and Conference. Society of Petroleum Engineers

Abdulraheem A, Ahmed M, Vantala A, Parvez T (2009) Prediction of rock mechanical parameters for hydrocarbon reservoirs using different artificial intelligence techniques. In: SPE Saudi Arabia Section Technical Symposium. Society of Petroleum Engineers
Abhvani AS, eaumont DN (1987) Development of an efficient algorithm for the calculation of two-phase flash equilibria. SPE Reservoir Eng 2(4):695-702

Adebayo AR, Abdulraheem A, Olatunji SO (2015) Artificial intelligence based estimation of water saturation in complex reservoir systems. J Porous Media 18:893-906. https://doi.org/10.1615/ JPorMedia.v18.i9.60

Ahmadi MA (2011) Prediction of asphaltene precipitation using artificial neural network optimized by imperialist competitive algorithm. J Pet Explor Prod Technol 1:99-106. https://doi. org/10.1007/s13202-011-0013-7

Ahmadi MA (2012) Neural network based unified particle swarm optimization for prediction of asphaltene precipitation. Fluid Phase Equilib 314:46-51. https://doi.org/10.1016/J.FLUID.2011.10.016

Ahmadi MA (2015a) Developing a robust surrogate model of chemical flooding based on the artificial neural network for enhanced oil recovery implications. Math Probl Eng 2015:1-9. https://doi. org/10.1155/2015/706897

Ahmadi MA (2015b) Connectionist approach estimates gas-oil relative permeability in petroleum reservoirs: application to reservoir simulation. Fuel 140:429-439. https://doi.org/10.1016/J. FUEL.2014.09.058

Ahmadi MA (2016) Toward reliable model for prediction Drilling Fluid Density at wellbore conditions: a LSSVM model. Neurocomputing 211:143-149. https://doi.org/10.1016/J.NEUCO M.2016.01.106

Ahmadi M-A, Bahadori A (2015) A LSSVM approach for determining well placement and conning phenomena in horizontal wells. Fuel 153:276-283. https://doi.org/10.1016/J.FUEL.2015.02.094

Ahmadi MA, Ebadi M (2014) Evolving smart approach for determination dew point pressure through condensate gas reservoirs. Fuel 117:1074-1084. https://doi.org/10.1016/J.FUEL.2013.10.010

Ahmadi MA, Mahmoudi B (2016) Development of robust model to estimate gas-oil interfacial tension using least square support vector machine: experimental and modeling study. J Supercrit Fluids 107:122-128. https://doi.org/10.1016/J.SUPFLU.2015.08.012

Ahmadi MA, Shadizadeh SR (2012) New approach for prediction of asphaltene precipitation due to natural depletion by using evolutionary algorithm concept. Fuel 102:716-723. https://doi. org/10.1016/J.FUEL.2012.05.050

Ahmadi M-A, Ahmadi MR, Hosseini SM, Ebadi M (2014a) Connectionist model predicts the porosity and permeability of petroleum reservoirs by means of petro-physical logs: application of artificial intelligence. J Pet Sci Eng 123:183-200. https://doi.org/10.1016/J. PETROL.2014.08.026

Ahmadi M-A, Masumi M, Kharrat R, Mohammadi AH (2014b) Gas analysis by in situ combustion in heavy-oil recovery process: experimental and modeling studies. Chem Eng Technol 37:409418. https://doi.org/10.1002/ceat.201300155

Ahmadi MA, Ebadi M, Hosseini SM (2014c) Prediction breakthrough time of water coning in the fractured reservoirs by implementing 
low parameter support vector machine approach. Fuel 117:579589. https://doi.org/10.1016/J.FUEL.2013.09.071

Ahmadi MA, Ebadi M, Marghmaleki PS, Fouladi MM (2014d) Evolving predictive model to determine condensate-to-gas ratio in retrograded condensate gas reservoirs. Fuel 124:241-257. https://doi. org/10.1016/J.FUEL.2014.01.073

Ahmadi MA, Ebadi M, Yazdanpanah A (2014e) Robust intelligent tool for estimating dew point pressure in retrograded condensate gas reservoirs: application of particle swarm optimization. J Pet Sci Eng 123:7-19. https://doi.org/10.1016/J.PETROL.2014.05.023

Ahmadi MA, Masoumi M, Askarinezhad R (2014f) Evolving connectionist model to monitor the efficiency of an in situ combustion process: application to heavy oil recovery. Energy Technol 2:811-818. https://doi.org/10.1002/ente.201402043

Ahmadi M-A, Bahadori A, Shadizadeh SR (2015a) A rigorous model to predict the amount of dissolved calcium carbonate concentration throughout oil field brines: side effect of pressure and temperature. Fuel 139:154-159. https://doi.org/10.1016/J.FUEL.2014.08.044

Ahmadi MA, Masoumi M, Askarinezhad R (2015b) Evolving smart model to predict the combustion front velocity for in situ combustion. Energy Technol 3:128-135. https://doi.org/10.1002/ ente. 201402104

Ahmadi MA, Zahedzadeh M, Shadizadeh SR, Abbassi R (2015c) Connectionist model for predicting minimum gas miscibility pressure: application to gas injection process. Fuel 148:202-211. https:// doi.org/10.1016/J.FUEL.2015.01.044

Ahmadi M-A, Hasanvand MZ, Bahadori A (2017) A least-squares support vector machine approach to predict temperature drop accompanying a given pressure drop for the natural gas production and processing systems. Int J Ambient Energy 38:122-129. https:// doi.org/10.1080/01430750.2015.1055515

Ahmed TH (2001) Reservoir engineering handbook [electronic resource]. Elsevier/Gulf Professional

Ali Ahmadi M, Ahmadi A (2016) Applying a sophisticated approach to predict $\mathrm{CO}_{2}$ solubility in brines: application to $\mathrm{CO}_{2}$ sequestration. Int J Low-Carbon Technol 11:325-332. https://doi.org/10.1093/ ijlct/ctu034

Alimohammadi S, Sayyad Amin J, Nikooee E (2017) Estimation of asphaltene precipitation in light, medium and heavy oils: experimental study and neural network modeling. Neural Comput Appl 28:679-694. https://doi.org/10.1007/s00521-015-2097-3

Al-Jawad MS (2010) Hassan OF (2010) Correlating optimum stage pressure for sequential separator systems. SPE Projects Facil Constr 5(1):13-16

Anifowose F, Labadin J, Abdulraheem A (2013) A least-square-driven functional networks type-2 fuzzy logic hybrid model for efficient petroleum reservoir properties prediction. Neural Comput Appl 23:179-190. https://doi.org/10.1007/s00521-012-1298-2

Arnold K, Stewart M (1999) Surface production operations. Volume 2, design of gas-handling systems and facilities. Elsevier, Amsterdam

Artun E (2017) Characterizing interwell connectivity in waterflooded reservoirs using data-driven and reduced-physics models: a comparative study. Neural Comput Appl 28:1729-1743. https://doi. org/10.1007/s00521-015-2152-0

Bahadori A, Vuthaluru HB, Mokhatab S (2008) Optimizing separator pressures in the multistage crude oil production unit. Asia-Pacific J Chem Eng 3:380-386. https://doi.org/10.1002/apj.159

Bazargan H, Adibifard M (2017) A stochastic well-test analysis on transient pressure data using iterative ensemble Kalman filter. Neural Comput Appl. https://doi.org/10.1007/s00521-017-3264-5

Baziar S, Shahripour HB, Tadayoni M, Nabi-Bidhendi M (2016) Prediction of water saturation in a tight gas sandstone reservoir by using four intelligent methods: a comparative study. Neural Comput Appl. https://doi.org/10.1007/s00521-016-2729-2
Cevik A, Sezer EA, Cabalar AF, Gokceoglu C (2011) Modeling of the uniaxial compressive strength of some clay-bearing rocks using neural network. Appl Soft Comput 11:2587-2594. https://doi. org/10.1016/j.asoc. 2010.10 .008

Clark NJ (1969) Elements of petroleum reservoirs, Rev edn. Society of Petroleum Engineers of AIME, Dallas

Elkatatny S, Tariq Z, Mahmoud M et al (2018) Development of new mathematical model for compressional and shear sonic times from wireline log data using artificial intelligence neural networks (white box). Arab J Sci Eng. https://doi.org/10.1007/s1336 9-018-3094-5

Elmabrouk S, Zekri A, Shirif E (2014) The prediction of bubble-point pressure and bubble-point oil formation volume factor in the absence of PVT analysis. Pet Sci Technol 32:1168-1174. https:// doi.org/10.1080/10916466.2011.569811

Elshafei M, Awady A (2013) Method for optimizing and controlling pressure in gas-oil separation plants

Fattahi H, Gholami A, Amiribakhtiar MS, Moradi S (2015) Estimation of asphaltene precipitation from titration data: a hybrid support vector regression with harmony search. Neural Comput Appl 26:789-798. https://doi.org/10.1007/s00521-014-1766-y

Ghaedi M, Ebrahimi AN, Pishvaie MR (2014) Application of genetic algorithm for optimization of separator pressures in multistage production units. Chem Eng Commun 201:926-938. https://doi. org/10.1080/00986445.2013.793676

Gunnerud V, Foss BA, McKinnon KIM, Nygreen B (2012) Oil production optimization solved by piecewise linearization in a Branch \& Price framework. Comput Oper Res 39:2469-2477. https://doi. org/10.1016/j.cor.2011.12.013

Hafskjold B, Celius HK, Aamo OM (1997) A new mathematical model for oil/water separation in pipes and tanks

Helmy T, Rahman SM, Hossain MI, Abdelraheem A (2013) Non-linear heterogeneous ensemble model for permeability prediction of oil reservoirs. Arab J Sci Eng 38:1379-1395. https://doi.org/10.1007/ s13369-013-0588-Z

Ling K, Wu X, Guo B, He J (2013) New method to estimate surfaceseparator optimum operating pressures. Oil Gas Facil 2(3):65-76

Nooruddin HA, Anifowose F, Abdulraheem A (2013) Applying artificial intelligence techniques to develop permeability predictive models using mercury injection capillary-pressure data. In: SPE Saudi Arabia Section Technical Symposium and Exhibition. Society of Petroleum Engineers

Passos AC, Teixeira MG, Garcia KC et al (2014) Using the TODIMFSE method as a decision-making support methodology for oil spill response. Comput Oper Res 42:40-48. https://doi. org/10.1016/j.cor.2013.04.010

Shujath Ali S, Hossain ME, Hassan MR, Abdulraheem A (2013) Hydraulic unit estimation from predicted permeability and porosity using artificial intelligence techniques. In: North Africa Technical Conference and Exhibition. Society of Petroleum Engineers

Sonmez H, Tuncay E, Gokceoglu C (2004) Models to predict the uniaxial compressive strength and the modulus of elasticity for Ankara Agglomerate. Int J Rock Mech Min Sci 41:717-729. https://doi. org/10.1016/j.jirmms.2004.01.011

Tariq Z, Elkatatny S, Mahmoud M, Abdulraheem A (2016a) A holistic approach to develop new rigorous empirical correlation for static Young's modulus. In: Abu Dhabi International Petroleum Exhibition \& Conference. Society of Petroleum Engineers

Tariq Z, Elkatatny S, Mahmoud M, Abdulraheem A (2016b) A new artificial intelligence based empirical correlation to predict sonic travel time. In: International Petroleum Technology Conference. International Petroleum Technology Conference

Tariq Z, Elkatatny S, Mahmoud M et al (2017a) A new approach to predict failure parameters of carbonate rocks using artificial 
intelligence tools. In: SPE Kingdom of Saudi Arabia Annual Technical Symposium and Exhibition. Society of Petroleum Engineers

Tariq Z, Elkatatny S, Mahmoud M et al (2017b) A new technique to develop rock strength correlation using artificial intelligence tools. In: SPE Reservoir Characterisation and Simulation Conference and Exhibition. Society of Petroleum Engineers
Yang Y, Rosenbaum MS (2002) The artificial neural network as a tool for assessing geotechnical properties. Geotech Geol Eng 20:149168. https://doi.org/10.1023/A:1015066903985

Publisher's Note Springer Nature remains neutral with regard to jurisdictional claims in published maps and institutional affiliations. 